\title{
HUBUNGAN DUKUNGAN KELUARGA DENGAN PEMBERIAN ASI PADA IBU POST PARTUM DI RUMAH SAKIT UMUM DAERAH KOTAMOBAGU
}

\author{
Pricilya Margaretha Warwuru ${ }^{1}$, Siska Sibua ${ }^{2}$, Novia Mokoagow ${ }^{3}$ \\ 1,2 Staff dosen Program Studi Keperawatan Institut Kesehatan dsn Teknologi Graha Medika Kotamobagu \\ 3 Mahasiswa Program Studi Keperawatan Institut Kesehatan dsn Teknologi Graha Medika Kotamobagu \\ Alamat Korespondensi:pricilya.margaretha@yahoo.com
}

\begin{abstract}
Abstrak
Air Susu Ibu (ASI) adalah ASI yang diberikan secara langsung oleh ibu kepada bayi tanpa melalui alat seperti pompa ASI. ASI juga memiliki kandungan sebagai antibodi yang melindungi bayi dari berbagai macam penyakit. Dampak yang terjadi di RSUD mengenai kurangnya dukungan keluarga pada ibu menyusui menjadi suatu hambatan ibu dalam menyukseskan ASI kepada bayinya. Tujuan dari penelitian ini untuk mengetahui hubungan dukungan keluarga dengan pemberian ASI pada ibu post partum di Rumah Sakit Umum Daerah Kotamobagu. Jenis penelitian ini adalah Deskriptif Analitk dengan menggunakan pendekatan Cross Sectional yaitu, untuk mencari hubungan antara variabel independen dengan variabel dependen, teknik pengambilan sampel yaitu accidental sampling jumlah sampel 32 responden yang termasuk dalam kriteria penelitian. Hasil uji statistic dengan menggunakan chi-square $\left(\mathrm{X}^{2}\right)$, pada tingkat kemaknaan $(\alpha: 0,05)$ di dapat hasil $\mathrm{p}$ value $=0,000$ ini berarti Ho ditolak, sehingga kesimpulannya yaitu ada hubungan yang signifikan antara hubungan dukungan keluarga dengan pemberian ASI di Rumah Sakit Umum Daerah Kotamobagu. Kesimpulan dari penelitian ini Yaitu ada hubungan dukungan keluarga dengan pemberian ASI pada ibu post partum di Rumah Sakit Umum Daerah Kotamobagu.
\end{abstract}

Kata Kunci: Dukungan Keluarga, Pemberian ASI, Ibu Post Partum

\begin{abstract}
Breast Milk (ASI) is given directly by the mother to the baby without going through the ASI. Breast Milk also has the content as an antibody that can protect baby from various diseases. The impact happened of hospital general Kotamobagu about family support mother also breastfeeding becomes an obstacle in success of breastfeeding to her baby. The aim of this study is to know and giving breast milk to postpartum mothers of hospital general Kotamobagu. Kind of research is analytic descriptive by using the approach cross sectional that is to looking for relationship between independent and dependent variables, sampling technique that is accidental sampling a sample of 32 respondents includ in the research criteria. Statistical test results by using chi-squere $\left(\mathrm{X}^{2}\right)$ at the level of significance $(\alpha: 0.05)$ the results obtained $\mathrm{p}$ value $=0,000$ means that Ho is rejected, so the conclusion is that there is a significant relationship between the relationship of family support with breastfeeding at Kotamobagu Regional General Hospital. That is, there is a relationship between family support and breastfeeding in post partum mothers at Kotamobagu Regional General Hospital.
\end{abstract}

Keywords: family support, breastfeeding, postpartum 


\section{PENDAHULUAN}

Hipertensi merupakan salah satu penyakit kronis yang WHO merekomendasikan untuk melakukan inisiasi menyusui dalam satu jam pertama kehidupan, bayi hanya menerima ASI tanpa tambahan makanan atau minuman, termasuk air, menyusui sesuai permintaan atau sesering yang diinginkan bayi, dan tidak menggunakan botol atau dot (WHO, 2018). Pemberian hanya ASI saja kepada bayi selama 6 bulan pertama kehidupannya, tanpa tambahan makanan atau minuman lainnya disebut dengan ASI eksklusif (WHO, 2014).

Data (Kesmankes RI, 2018) tetang IMD (Insiasi Menyusui Dini) di Sulawesi Utara bayi yang mendapatkan IMD kurang dari 1 jam mencapai $32,42 \%$ dan yang lebih dari 1 jam yaitu, 5,15. IMD ( inisiasi menyusui dini). Faktor lainnya yang menjadi penghambat ialah lingkungan ibu menyusui mulai dari keluarga yang tidak memberikan dukungan untuk pemberian ASI eksklusif dan lingkungan pekerjaan bagi ibu pekerja yang tidak menyediakan ruang untuk memberikan ASI atau tempat untuk menyimpannya.

Berdasarkan data Dinas Kesehatan tahun 2018, dari 5 Puskesmas yang ada di Kotamobagu, cakupan ASI paling rendah ada di wilayah kerja Puskesmas Bilalang sebesar 0,0\%, dalam pemberian ASI sebesar 0 dan tidak eksklusif 7. Cakupan pada wilayah kerja Puskesmas Bilalang ini masih rendah dari target yang di capai dalam pemberian ASI, faktor penyebab yang memicu kuranagnya ASI kepada bayi baru lahir berupa kurangnya pengetahuan dan dukungan (suami dan ortang tua), (Dinas Kesehatan Kotamobagu, 2018). Rendahnya pemberian ASI merupakan ancaman bagi tumbuh kembang anak yang akan berpengaruh pada pertumbuhan dan perkembangan kualitas sumber daya manusia secara umum (Hidayah, 2018).

Satu jam kehidupan pertamanya setelah dilahirkan ke dunia, pastikan mendapatkan kesempatan untuk melakukan Inisiasi Menyusu Dini (IMD). IMD adalah proses meletakkan bayi baru lahir pada dada atau perut sang ibu agar bayi secara alami dapat mencari sendiri sumber air susu ibu (ASI) dan menyusu. Sangat bermanfaat karena bayi akan mendapatkan kolostrum yang terdapat pada tetes ASI pertama ibu yang kaya akan zat kekebalan tubuh. Tidak hanya bagi bayi, IMD juga sangat bermanfaat bagi Ibu karena membantu mempercepat proses pemulihan pasca persalinan. Meskipun manfaatnya begitu besar, banyak ibu yang tidak berhasil mendapatkan kesempatan IMD, karena kurangnya pengetahuan dan dukungan dari lingkungan (suami, orang tua dan bertua).Selanjutnya, berikan hanya ASI saja bagi bayi sejak lahir hingga usia 6 bulan, hal ini bukanlah sebuah hal yang mudah bagi seorang ibu bila tidak didukung oleh pasangan, keluarga dan seluruh stakeholder di sekitarnya. Seorang ibu menyusui harus dijaga, semua harus mendukung dan menjaga (Kemenkes 2017).

Berdasarkan Survei awal yang dilakukan peneliti di RSUD Kotamobagu tanggal 30 Januari 2019, jumlah ibu post partum bulan (November, desember 2018 dan 
januari 2019) sebanyak 94. Hasil observasi yang dilakukan pada $5 \mathrm{ibu}$ post partum dan 2 di antaranya memberikan susu formula yang dimana langsung diberikan suami dari ibu tersebut dan terdapat juga susu formula di ruangan ibu saat sedang melakukan observasi.Hal ini di sebabkan oleh kurangnya dukungan keluarga kepada ibu menyusui.Hasil wawancara dari 2 ibu post partum dan keluarga mereka tidak sepenuhnya memberikan ASI kepada bayi, akan tetapi di berikan juga makanan tambahan seperti susu formula. Informasi yang di dapat dari tenaga kesehatan yang dinas di ruangan Nifas kelas III pada saat itu, telah memberikan arahan mengenai cara pemberian ASI secara baik dan benar, jika di lihat dari data dan informasi yang didapat mengenai dukungan keluarga dalam pemberian ASI pada ibu post partum, masih kurang karena pada waktu itu ada ibu yang didampingi suami dan mertua ibu tersebut (RSUD Kotamobagu 2019).

\section{METODE PENELITIAN}

Jenis penelitian ini adalah Deskriptif Analitk dengan menggunakan pendekatan Cross Sectional yang dilakukan di Rumah Sakit Umum Daerah Kotamobagu pada Bulan AprilMei 2019.. Populasi dalam penelitian ini jumlah ibu post partum yang melahirkan secara normal di ruangan Nifas RSUD Kotamobagu sebanyak 94 responden di 3 bulan terakhir (November, Desember 2018 dan Januari 2019. Sampel penelitian adalah 32 responden dengan menggunakan teknik accidental sampling.

Alur penelitian ini adalah dengan cara memberikan sebuah kuesioner mengenai dukungan keluarga dan pemberian ASI kepada responden yang di dalam kuesioner terdapat pertanyaanpertanyaan yang harus dijawab setiap responden (HSMBQ). Pengumpulan data dilakukan dengan memberikan kuesioner di ruang tunggu pengambilan obat puskesmas dengan estimasi waktu 15-20 menit. Data yang terkumpul kemudian ditabulasi kedalam matriks pengumpulan data yang telah dibuat sebelumnya oleh peneliti dan kemudian dilakukan analisa data. Dalam hal ini peneliti menggunakan skala nominal, Sehingga digunakan rumus Chi Square $\left(\mathrm{X}^{2}\right)$ dua variabel dengan tingkat kemaknaan $95 \%(\alpha \leq 0,05)$ jika $p$ value $<0,05$ maka $\mathrm{Ha}$ diterima, artinya terdapat hubungan dukungan keluarga dan pemberian ASI pada ibu post partum di RSUD Kotamobagu, Jika $\mathrm{p}$ value > 0,05 maka Ho tidak diterima, artinya tidak hubungan dukungan keluarga dan pemberian ASI pada ibu post partum di RSUD Kotamobagu

\section{HASIL PENELITIAN}

Tabel 1. Distribusi Frekuensi Responden Menurut Umur Di Ruangan Nifas Rumah Sakit Umum Daerah Kotamobagu 2019

\begin{tabular}{lll}
\hline $\begin{array}{l}\text { Karakteristik Umur } \\
\text { Responden }\end{array}$ & $\begin{array}{l}\text { Frekuensi } \\
\text { (f) }\end{array}$ & $\begin{array}{l}\text { Presentase } \\
(\boldsymbol{\%})\end{array}$ \\
\hline $\begin{array}{l}\text { Remaja Awal 12-16 tahun } \\
\text { Remaja Akhir 17-25 Tahun }\end{array}$ & 2 & 6,2 \\
\end{tabular}




\begin{tabular}{lll} 
Dewasa Awal 26-35 Tahun & 11 & 34,4 \\
Dewasa Akhir 36-45 Tahun & 3 & 9,4 \\
\hline Total & $\mathbf{3 2}$ & $\mathbf{1 0 0}$ \\
\hline
\end{tabular}

Tabel 2 Distribusi Frekuensi Responden Menurut Jarak Anak Di Ruangan Nifas Rumah Sakit Umum Daerah Kotamobagu 2019

\begin{tabular}{ccc}
\hline $\begin{array}{c}\text { Karakteristik Jumlah } \\
\text { Anak Responden }\end{array}$ & $\begin{array}{c}\text { Frekuensi } \\
(\mathbf{f})\end{array}$ & $\begin{array}{c}\text { Presentase } \\
(\boldsymbol{\%})\end{array}$ \\
\hline$<1$ Tahun & 17 & 53,1 \\
$>1$ Tahun & 13 & 46,9 \\
\hline Total & $\mathbf{3 0}$ & $\mathbf{1 0 0}$ \\
\hline
\end{tabular}

Tabel 3 Distribusi Frekuensi Responden Menurut Pendidikan Di Ruangan Nifas Rumah Sakit Umum Daerah Kotamobagu 2019

\begin{tabular}{lcc}
\hline $\begin{array}{l}\text { Karakteristik Pendidikan } \\
\text { Responden }\end{array}$ & $\begin{array}{c}\text { Frekuensi } \\
(\mathbf{f})\end{array}$ & $\begin{array}{c}\text { Presentase } \\
(\boldsymbol{\%})\end{array}$ \\
\hline SD & 8 & 25,0 \\
SMP & 7 & 21,9 \\
SMA/SMK & 12 & 37,5 \\
S1 & 5 & 15,6 \\
Total & $\mathbf{3 2}$ & $\mathbf{1 0 0}$ \\
\hline
\end{tabular}

Tabel 4 Distribusi Frekuensi Responden Menurut Pekerjaan Di Ruangan Nifas Rumah Sakit Umum Daerah Kotamobagu 2019

\begin{tabular}{lcc}
\hline Karakteristik Pendidikan & Frekuensi & $\begin{array}{c}\text { Presentase } \\
\text { Responden }\end{array}$ \\
& $(\mathbf{f})$ & $(\boldsymbol{\%})$ \\
\hline IRT & 20 & 62,5 \\
Wiraswasta & 2 & 6,3 \\
Guru & 4 & 12,5 \\
Perawat & 2 & 6,3 \\
Tani & 3 & 9,4 \\
Pelajar/mahasiswa & 1 & 3,1 \\
\hline Total & $\mathbf{3 2}$ & $\mathbf{1 0 0}$ \\
\hline
\end{tabular}

Tabel 5. Distribusi Frekuensi Responden Menurut Dukungan Keluarga Di Ruangan Nifas Rumah Sakit Umum Daerah Kotamobagu 2019

\begin{tabular}{ccr}
\hline Karakteristik Dukungan & Frekuensi & Presentase \\
Keluarga Responden & (f) & $(\boldsymbol{\%})$ \\
\hline Suami & 24 & 75,0 \\
Orang Tua & 6 & 18,8 \\
Mertua & 2 & 6,3
\end{tabular}




\begin{tabular}{lll}
\hline Total & 32 & 100 \\
\hline
\end{tabular}

Tabel 6 Distribusi Frekuensi Kategori Menurut Dukungan Keluarga Di Rungan Rungan Nifas Rumah Sakit Umum Daerah Kotamobagu 2019

\begin{tabular}{lcc}
\hline Dukungan Keluarga & $\begin{array}{r}\text { Frekuensi } \\
(\mathbf{f})\end{array}$ & $\begin{array}{c}\text { Presentase } \\
(\boldsymbol{\%})\end{array}$ \\
\hline Kurang Baik & 16 & 50,0 \\
Baik & 16 & 50,0 \\
\hline Total & $\mathbf{3 2}$ & $\mathbf{1 0 0}$
\end{tabular}

Tabel 7 Distribusi Frekuensi Menurut Pemberian ASI Di Rungan Nifas Rumah Sakit Umum Daerah Kotamobagu 2019

\begin{tabular}{lcc}
\hline Pemberian ASI & $\begin{array}{c}\text { Frekuensi } \\
(\mathbf{f})\end{array}$ & $\begin{array}{c}\text { Presentase } \\
(\boldsymbol{\%})\end{array}$ \\
\hline Tidak Memberikan ASI & 13 & 40,6 \\
Memberikan ASI & 19 & 59,4 \\
\hline Total & $\mathbf{3 2}$ & $\mathbf{1 0 0}$ \\
\hline
\end{tabular}

Tabel 8 Distribusi hubungan dukungan keluarga dengan pemberian ASI pada ibu post partum di Rumah Sakit Umum Daerah Kotamobagu 2019.

Pemberian ASI Total

\begin{tabular}{|c|c|c|c|c|c|c|c|c|}
\hline \multirow{3}{*}{$\begin{array}{l}\text { Dukungan Tidak } \\
\text { Keluarga n }\end{array}$} & \multicolumn{5}{|c|}{ Memberikan } & \multicolumn{2}{|c|}{ (OR95\% CI) } & \\
\hline & \multicolumn{3}{|c|}{ Memberikan ASI } & \multicolumn{2}{|c|}{ ASI } & & \multicolumn{2}{|c|}{$P$ value } \\
\hline & $\%$ & $\mathrm{n}$ & $\% \mathrm{~N}$ & $\%$ & & & & \\
\hline \multirow[t]{2}{*}{ Kurang Baik } & 1 & 6,3 & 15 & 93,8 & 16 & 100 & & \\
\hline & & & & & & & 25.000 & 0.001 \\
\hline Baik & 12 & 75,0 & 4 & 25,0 & 16 & 100 & & \\
\hline Jumlah & 13 & 40,6 & 19 & 59,4 & 32 & 10 & & \\
\hline
\end{tabular}




\section{PEMBAHASAN}

Hasil penelitian ditemukan bahwa responden yang umur $17-25$ tahun sebanyak 16 responden $(50,0 \%)$ lebih dominan. Menurut Untari 2017 Umur 20-35 tahun merupakan usia reproduksi sehat bagi seorang wanita, sedangkan usia > 35 tahun termasuk usia berisiko pada usia reproduksi namun bila dilihat dari aspek perkembangan maka usia $>35$ tahun memiliki perkembangan yang lebih baik secara psikologis atau mental. Pada penelitian Mamangkey 2018 bahwa distribusi responden menurut umur ditemukan paling banyak ditemukan pada umur 21-25 tahun sebanyak 48 orang $(44.6 \%)$ dan paling sedikit pada kelompok umur 31-35 tahun yaitu 12 orang $(11,7 \%)$. Sedangkan, pada usia 12-16 tahun sebanyak 2 orang $(6,2 \%)$

Berdasarkan tabel 5.1 menunjukan bahwa responden yang umur 17-25 tahun sebanyak 16 responden $(50,0 \%)$ lebih dominan. Menurut Untari 2017 Umur 20-35 tahun merupakan usia reproduksi sehat bagi seorang wanita, sedangkan usia > 35 tahun termasuk usia berisiko pada usia reproduksi namun bila dilihat dari aspek perkembangan maka usia > 35 tahun memiliki perkembangan yang lebih baik secara psikologis atau mental. Pada penelitian Mamangkey 2018 bahwa distribusi responden menurut umur ditemukan paling banyak ditemukan pada umur 21-25 tahun sebanyak 48 orang $(44.6 \%)$ dan paling sedikit pada kelompok umur 31-35 tahun yaitu 12 orang $(11,7 \%)$. Sedangkan, pada usia 12-16 tahun sebanyak 2 orang $(6,2 \%)$

Berdasarkan tabel 5.2 menunjukan bahwa responden yang memiliki jumlah anak dengan kehamilan pertama sebanyak 17 responden $(53,1 \%)$. Penelitian yang di lakukan Untari 2017 Untuk jarak kelahiran dengan anak terakhir sebagian besar ibu tidak memberikan Asi adalah > 1 tahun yaitu 27 orang $(67,5 \%)$. Menurut United States Agency (USAID) tahun 2017 batas jarak kelahiran optimal adalah batas waktu antar kelahiran yang menghasilkan dampak kesehatan yang terbaik bagi kehamilan, ibu, bayi baru lahir, dan seluruh keluarga.

Berdasarkan tabel 5.3 menunjukan bahwa responden yang memiliki tingkat pendidikan SMA/SMK sebanyak 12 responeden $(37,5 \%)$. Menurut Untari (2017) Pendidikan akan membuat seseorang terdorong untuk ingin tahu, untuk mencari pengalaman dan untuk mengorganisasikan pengalaman sehingga informasi yang diterima akan menjadi pengetahuan. Pendidikan yang tinggi membuat seorang ibu lebih dapat berfi kir rasional tentang manfaat Asi dan pendidikan tinggi lebih mudah untuk terpapar dengan informasi dibandingkan dengan yang berpendidikan rendah.

Berdasarkan tabel 5.7 menunjukan bahwa reponden dengan kategori dukungan keluarga yang baik sebanyak 16 responden $(50,0 \%)$. Penelitian yang dilakukan Andriani 2017 Menunjukan bahwa responden yang memiliki dukungan keluarga yang baik berjumlah 22 responden $(73 \%)$, kurang baik 3 responden (10\%). Andarini (2017) mengemukakan bahwa dukungan keluarga merupakan factor pendorong ibu untuk memberikan ASI, salah satu bentuk dukungan keluarga berupa pemberian bantuan dari bentuk materi, bantuan fisik berupa alat atau lainnya yang mendukung ibu dalam proses menyusui.

Menurut pendapat peneliti dukungan yang baik akan membatu dan memotivasi ibu dalam melakukan halhal yang diinginkan seprti menyusui 
secara rutin tidak hanya di rumah sakit akan tetapi dilakukan juga di rumah selepas perawatan di Rumah Sakit. Berdasarkan tabel 5.9 menunjukan bahwa dukungan keluarga yang kurang baik tidak memberikan ASI 15 responden $(93,8 \%)$, sedangkan dukungan keluarga baik tapi memberikan ASI 1 responden $(6,3)$, dukungan keluarga dalam hal ini menjadi pondasi bagi ibu menyusui agar supaya memberikan ASI kepada bayi, dengan bagitu banyak responden yang dukungan keluarga kurang baik tidak memberikan ASI degnan alasan 15 keluarga tersebut kurang memberikan dukungan yang penuh kepada ibu menyusui berupa informasi-inforamasi tentang ASI dan manfaat ASI. Penelitian ini sejalan dengan hasil peneliitan Eliana (2018) yaitu sebagian besar dukungan keluarga ibu dengan pemberian ASI di wilaya kerja Puskesmas Sekaran Kecamatan Gunungpati tidak mendukung yaitu 33 responden (720,2\%).Anggorowati (2015) ASI sangat diperlukan untuk pertumbuhan dan perkembangan kecerdasan anak.Menurut Suryani (2017)Ibu menyusui kadang mengalami masalah psikologi, fluktuasi hormon lalu perubahan rutinitas membuat kondisi psikologi dan fisik ibu menjadi tidak stabil, disini ibu membutuhkan dukungan keluarga terutama suami.

Penelitian ini membuktikan terdapat hubungan yang signifikan dan bermakna antara dukungan keluarga dengan pemberian ASI pada ibu post partum di Rumah Sakit Umum Daerah Kotamobagu. Dari hasil analisis di peroleh uji statistic dengan menggunakan chi-square menya $\left(\mathrm{X}^{2}\right)$, pada tingkat kemaknaan 95\% $(\alpha: 0,05)$ di dapat hasil $p$ value $=0,001$. Berdasarkan hasil analisis diperoleh pula nilai $\mathrm{OR}=25,000$ artinya keluarga yang memiliki dukungan baik mempunyai peluang 25 kali untuk melakukan pemberian ASI pada ibu post partum. Hasil penelitian ini sejalan dengan penelitian yang dilakukan oleh Utami (2018) dengan hasil dukungan keluarga baik memberikan ASI sebanyak 24 responden $(82,8)$, dengan hasil uji statistic dengan menggunakan chi square di dapatkan hasil $p$ value $<0,05$ sehingga dapat disimpulkan bahwa ada hubungan antara dukungan keluarga dengan pemberian ASI.

\section{KESIMPULAN DAN SARAN}

Ada hubungan yang signifikan antara hubungan dukungan keluarga dengan pemberian ASI di Rumah Sakit Umum Daerah Kotamobagu. Sebagian besar responden mendapat dukungan keluarga yang baik dala pemberia asi ekslusif. Dukungan yang kurang baik terhadap ibu menyusui akan terjadi hambatan ibu memberi ASI kepada bayinya. Hasil penelitian ini dapat dijadikan bahan masukan unuk tenaga kesehatan terkhusus di Ruangan Nifas agar meningkatkan pengetahuan mengenai pentingnya dukungan keluaga kepada ibu menyusui agar terus memberikan ASI kepada bayi dan tidak hanya di Rumah Sakit saja akan tetapi sampai dengan usia yang telah ditetapkan yaitu 6 bulan. Penelitian ini dijadikan bahan referensi untuk melakukan penelitian selanjutnya khususnya penelitian dengan judul yang sama baik di lakukan di RS atau tempat pelayanan lainnya.

\section{DAFTAR PUSTA}

Aldaudy.U.C dan Fithria, 2018.Pengetahuan Ibu Tentang Asi Eksklusif. Di unduh pada tanggal 30 Januari 2019, Time: 07.29

Anggorowati.2015. Hubungan Antara Dukungan Keluarga Dengan Pemberian ASI Pada Bayi Di Desa Bebengan Kecamatan Boja Kabupaten Kendal. 26 Mei 2019 
Andriani D. 2017.Dukungan Keluarga Dengan Pemberian ASI Pda Ibu Menyusui. 26 Mei 2019

Dinkes. 2018. Cakupan pemberian ASI eksklusif. Kotamobagu.

Djitowiyono.S., 2017.Buku Asuhan Keperawatan Neonatus Dan Anak. Nuha Medika. Yongyakarta.

Donsu.T.D.J, 2017.Buku Metodologi Penelitian Keperawatan. Pustaka Baru Press:Yongyakarta.

Ernawati. J. 2018. Hubungan Dukungan Keluarga Terhadap Efikasi Diri Ibu Menyusui Dalam Memberikan Asi. 26 Mei 2019.

Fitri.I. , 2018. Buku Nifas, Kotrasepsi Terkini Dan Keluarga Berencana. Gosyen Publishing, Yongyakarta.

Fikawati. S. Dan Syafiq. A. Dan Karima. K, 2015.Buku Gizi Ibu Dan Bayi. PT RajaGrafindo Persada, Jakarta .

Haryono, Rudi dan Sulis setianingsih. 2014. Manfaat Asi Eksklusif Untuk Buah Hati Anda. Yogyakarta: Gosyen.

Hedianti .D.A. 2014 Dukungan Keluarga Dan Praktik Pemberian ASI Di Puskesmas Pucang Sewu Surabaya.26 Mei 2019.

Kementerian Kesehatan RI. 2017. Pedoman penyelengaraan Pekan ASI Sedunia

(PAS). Jakarta: Kementerian Kesehatan Republik Indonesia.

Kementrian Kesehatan RI, 2016 Separuh bayi di Indonesia tidak dapat ASI Eksklusif.

Mamangkey.F.J.S Dan Rompas. S, Dan Masi. G, 2018.Hubungan Dukungan Keluarga Dengan Pemberian Asi Eksklusif Pada Bayi Di Puskesmas Ranotana Weru. di unduh tangal 28 Januari 2019, jam : 11.00

Ni'mah. L.N, 2017.Faktor-Faktor Yang Mempengaruhi Keberhasilan Pemberian Asi Eksklusif Pada Ibu Bekerja. Fakultas Kedokteran Dan Ilmu Kesehatan Universitas Islam Negeri Syarif Hidayatullah Jakarta.
Nopria. R. Dan Ernawaty. J. Dan Jumaini. Hubungan Dukungan Keluarga Dengan Pemberian Asi Eksklusif Pada Ibu Yang Bekerja. Di Unduh Tanggal 28 Januari 2019, Jam: 00.40.

Nursalam, 2013.Metodologi Penelitian Ilmu Keperawatan. Salemba Medika, Jakarta.

PAS, 2017.Pedoman Penyelengaraan Pekan ASI Sedunia, Jakarta.

Permatasari.I.E, 2018.Skripsi Hubungan Tingkat Kepuasan Ibu Terhadap Pelayanan 2 Jam Post partum Di Rumah Sakit Umumdaerah Dolopo Kabupaten Mediun. STIKES Hafshawty Zainul Hasan Genggong.

Purwoastuti. E. Dan Walyani. S.E. 2015.Buku Ilmu Kesehatan Dalam Kebidanan Konsep Teori Dan Aplikasi. PustakaBaruPress, Yongyakarta.

Putri.H.D, 2018.Hubungan Tingkat Pengetahuan Ibu, Status Pekerjaan Ibu Dan Dukungan Keluarga Dengan Pemberian ASI Eksklusif Di Wilayah Kerja Puskesmas Air Dingin Kota Padang Tahun 2018.Diploma thesis, Universitas Andalas.

Sahar J dkk, 2916.Dukungan Keluarga Terhadap Pemberian ASI Pada Bayi Di Kita Jambi.

Sandewi, 2018.Hubungan Pemberian Asi Eksklusif Dengan Pertumbuhan Dan Perkembangan Pada Bayi Usia 7-12 Bulan Di Wilayah Kerja Puskesmas Poasia. Politeknik Kesehatan Kediri.

Simbolon. P, 2017 Buku Dukungan Keluarga Dalam Pemberian ASI Eksklusif. DeeppublihRSUD Kotamobagu, 2019.Jumlah Pasien Post partum.Tanggal 30 Januari.

Tika.S, 2017.Hubungan Dukungan Keluarga Pada Ibu Post partum Blues Berdasarkan Tingkat Keparahan Di Rs Reomsni Muhamdyah 
Semarang.Unuversitas

Muhammadiyah Semarang.

Untari Jati. 2017. Hubungan Antara Karakteristik Ibu Dengan Pemberian Asi Eksklusif Di Wilayah Kerja Puskesmas Minggir Kabupaten Sleman. Di undu pada tanggal 25 mei 2019 jam : 03.00.

Vitasary. D. Dan Sabrian. F. Dan Ernawaty. J, 2018.hubungan Dukungan Keluarga Terhadap Efikasi Diri Ibu Menyusui Dalam Memberikan Asi Eksklusif. di unduh tanggal 29 Januari 2019, Jam: 00.21
Walyani, 2017.Buku Asuhan Kebidanan Masa Nifas \& Menyusui Pustaka Baru.Press Yogyakarta.

Walyani, 2015.Buku Perawatan Kehamilan Dan menyusui Anak Pertama Agar Bayi Lahir Dan Tumbuh Sehat.Pustaka Buku Pres, Yongyakarta.

World Health Organization WHO, 2013.Pemberian ASI Eksklusif Dan Pertumbuhan Bayi.Wicaksono 2015

World Health Organization (WHO). 2018. Exclusife Breastfeeding. 